\title{
A longa crise da educação: um problema de colonialidade
}

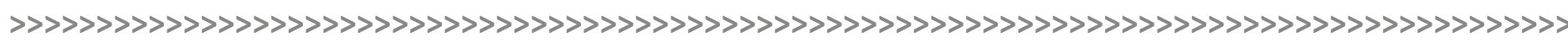

\author{
João Paulo Buchholz*
}

\section{Resumo:}

O presente trabalho pretende divagar sobre os problemas que a escola pública, a história e o seu ensino vem enfrentando, por meio de uma perspectiva de análise situada desde nuestra América: o pensamento decolonial. Problematizando a Colonialidade que existe e persiste em nossas estruturas, como a escola, a universidade e, até mesmo, os intelectuais, este trabalho pretende discutir sobre o desajuste que há entre as realidades latino-americanas e os corpos teóricos que a interpretam. Por conta disso, este artigo propõe a interculturalidade como ferramenta fundamental para fazer emergir alternativas para os problemas latino-americanos.

\section{Palavras-chave:}

Decolonialidade. Ensino de História. Interculturalidade. Vivência intercultural.

\section{Resumen:}

Lo seguinte trabajo pretende reflejar cerca de los problemas de la escuela pública, la Historia y su enseñanza se ha enfrentado, a través de una perspectiva de alalisis ubicada desde nuestra América: el Pensamiento Decolonial. Reflejando cerca de la Colonialidad que existe y persiste em nuestras estructuras, como la escuela, la universidad y hasta mismo los intelectuales, este trabajo pretende apaciguar el desajuste existiente cercano de las realidades latinoamericanas y las teorías que interpretan. Así, este artículo propone la Interculturalidad como herramienta indispensable para hacer emergir alternativas para los problemas latinoamericanos.

\section{Palabras-clave:}

Decolonialidad. Enseñanza de História. Interculturalidad. Experiencia Intercultural.

\section{Introdução}

Desde a década de 1930, talvez até mesmo antes, a escola e o nosso modelo de ensino vem sendo constantemente postos em xeque, vistos com desconfiança, definidos sempre a partir do conceito: crise. Gosto de pensar nesta situação com o apoio da seguinte metáfora recitada pelo Subcomandante Insurgente Marcos "houve um tempo em que as pautas se definiam de um centro geográfico e, daí se estendiam até a periferia, como uma pedra arremessada no centro de um tanque cheio de água, no qual, a onda que é produzida chega até a borda de maneira parcial e distorcida" (MARCOS, 2008, p. 33). Creio que algo parecido ocorre com a Escola e com o ensino de História no continente americano. As "pedras conceituais" da educação (e da ciência moderna, por que não?) foram - e ainda

\footnotetext{
* > Graduando em Licenciatura em História pela UFRGS.

E-mail: joao.buchholz@gmail.com
} 
são - arremessadas de um outro Locus de Enunciação (países de língua alemã, inglesa e francesa), produzindo uma onda que atravessa o Atlântico e chega a Latino América de maneira completamente parcial e distorcida.

É essa onda, ou melhor, a distância entre um locus e outro que produz esta sensação de desajuste, de que algo não encaixa, é como se houvesse uma náusea, um mal-estar difícil de diagnosticar. Entretanto, considera-se pouco científica a argumentação embasada em experiências sensoriais, de maneira que, comumente se traduz este mal-estar como "crise".

Não pretendo - e nem tenho possibilidades $d e$ - apresentar as "verdadeiras" questões por trás dos problemas educacionais, muito menos menosprezar a significativa produção que tem sido feita sobre este tema. A intenção é apresentar estes problemas por outra perspectiva, situada desde nuestra América, almejando apaziguar este problema teórico.

Pretendo colocar este mal-estar como um desajuste entre teoria e realidade, ou melhor, pela inequidade entre o locus de enunciação que produz a teoria e o locus que se adapta a ela. Desta forma, a concepção de ciência moderna; a concepção de Escola e Universidade; e a concepção de disciplina de História, são extremamente constitutivas deste desajuste entre teoria/realidade (especialmente a realidade latino-americana).

\section{O conhecimento moderno}

A ciência moderna surge apropriando-se de todas as demais formas de se produzir conhecimento. De modo geral, os conhecimentos "não científicos" continuam sendo constitutivos dos saberes ditos científicos até hoje, assim como o usufruto de mão de obra semiescrava e servil são constitutivos da centralidade do domínio capitalista atual.

O que pretendo problematizar sobre a consolidação da ciência moderna é a apropriação feita de diversas outras formas de se produzir conhecimento e de interpretar o mundo, julgando-as como formas inválidas ou inferiores de produção de conhecimento. Além disso, será questionada a forma como as ciências sociais e humanas, mais particularmente a História, tentaram emular o mesmo método de análise das ciências exatas, corroborando, dessa forma, com a naturalização de certos problemas sociais.

No que se refere à forma científica de produzir conhecimento, destaco que a ciência moderna é uma forma eurocêntrica e secularizada de produção intelectual, sendo assim, daqui em diante, tratarei essa ciência como "ocidental”.

\section{Galileu e o conhecimento válido}

A ciência ocidental é, atualmente, encarregada de definir quais são os conhecimentos "válidos" e "inválidos". Por conta disso, todas as outras formas de produzir conhecimento, que não são ocidentais, recebem algum adjetivo (tradicional, tribal, ancestral) para diferenciá-las da única forma "válida" de se produzir conhecimento: a ciência ocidental".

Para ilustrar esta distinção entre os conhecimentos "tradicionais" e "regionais",

1 > Aprecio o termo ciência "ocidental", pois ele esclarece o locus no qual se está produzindo esse conhecimento, já que o conhecimento ocidental se propõe como universal, em contraposição aos conhecimentos "andinos", "maias", "yorubás" e "orientais", que são regionais. Esta pretensão de universalidade é fruto do padrão de hegemonia europeia, constituída a partir do século XVIII. As implicações dessa pretensão de universalidade serão desastrosas para a disciplina histórica, como veremos adiante. perante o "inequívoco" e universal conhecimento ocidental, apresento um trecho do poema Os ninguéns, de Eduardo Galeano:

Os ninguéns: os filhos de ninguém, os donos de nada.

Os ninguéns: os nenhuns, correndo soltos, morrendo na vida, fodidos e mal pagos:

Que não são, embora sejam.

Que não falam idiomas, falam dialetos.

Que não praticam religiões, praticam superstições. 
Que não fazem arte, fazem artesanato.

Que não são seres humanos, são recursos humanos.

Que não têm cultura, têm folclore.

Que não têm cara, têm braços.

Que não têm nome, têm número.

Que não aparecem na história universal, aparecem nas páginas policiais.

Os ninguéns, que custam menos do que a bala que os mata. (GALEANO, 2002, p. 42).

O poema de Galeano consegue ilustrar de maneira explícita a condição de Colonialidade do Saber existente entre ocidentais/não ocidentais. O conceito de Colonialidade do Saber vem sendo desenvolvido por pesquisadores de nuestra América desde meados dos anos 1990, sendo a principal obra desta corrente de pensamento o livro organizado por Edgardo Lander (2000), Colonialidade do Saber: eurocentrismo e ciências sociais. Perspectivas Latino-americanas. Este livro possui a contribuição de diversos autores, dentre eles: Walter Mignolo, Aníbal Quijano, Ramon Grosfoguel e Santiago Castro-Gomez, cada um destes autores faz uma abordagem diferente em torno do tema. Para definir rapidamente, cito Catherine Walsh:

La colonialidad del saber [...] no sólo estableció el eurocentrismo como perspectiva única de conocimiento, sino que al mismo tiempo, descartó por completo la producción intelectual indígena y afro como 'conocimiento' y, consecuentemente, su capacidad intelectual (WALSH, 2007, p. 104)².

É esta a relação que vemos no poema de Galeano, os saberes não-ocidentais são, como afirma Maldonado Torres $\left(2007\right.$, p. 147) ${ }^{3}$, sempre "vistos com desconfiança".

Apresento um exemplo claro desta "desconfiança", para isso, tomo emprestadas as palavras de Luís Fernando Sarango Macas, reitor da Universidade Comunitária Intercultural dos Povos Indígenas Amawatay Wasi, do Equador. Palavras mais, palavras menos: “[...] a matemática e a geometria Inca eram, e ainda são, extremamente sofisticadas, porém, os matemáticos ocidentais as classificam como etno-matemática e etno-geometria (SARANGO, 2014)4." Como fica evidente, os saberes andinos recebem um adjetivo que o diferencia do conhecimento válido e universal: “etno”. Outro apontamento muito interessante feito por Sarango é sobre a validade do conhecimento: "os Incas, assim como os chineses, conheciam o valor de $\pi$ há uns mil anos antes de Galileu ser condenado por produzir um conhecimento inválido". 5 Saliento que a Igreja Católica era a instituição que dava respaldo ao conhecimento produzido na época. Atualmente, esta é uma incumbência de um órgão secularizado: a Universidade.

Antes de inferir sobre o papel que a universidade ocupa hoje, como fixadora e validadora de parâmetros eurocêntricos de produção de conhecimento, mencionarei, brevemente, o problema gerado pela emulação de valores das ciências exatas (observação, objetividade e neutralidade), por parte das ciências sociais e das humanidades.

Um forte exemplo desta emulação é o conceito de "classe" social. Aníbal Quijano possui um interessante trabalho sobre a genealogia deste conceito. Após pesquisar sobre o tema, Quijano nos evidencia que a origem do conceito de classe vem dos estudos naturais do século XVIII, mais especificamente dos estudos de Botânica (QUIJANO, 2000). Fica evidente a incongruência deste método de estudo, uma vez que, tal categoria de análise contribui mais para naturalizar determinado fato, do que para constituí-lo historicamente. Portanto, de acordo com Quijano, a naturalização de um fato social é o mesmo que negar sua historicidade.
$2>$ "A colonialidade do saber [...] não apenas estabeleceu o eurocentrismo como perspectiva única de conhecimento, como também ao mesmo tempo descartou por completo a produção intelectual indígena e afro como 'conhecimento' e, consequentemente, sua capacidade intelectual"(Tradução nossa).

3 > Maldonado Torres possui um importante trabalho sobre as implicações da Colonialidade do Saber (Colonialidade epistêmica) na Colonialidade do Ser (Colonialidade ontológica), no qual ele apresenta as implicações ontológicas em uma etnia que tem seus saberes vistos, como diz o autor, com desconfiança (MALDONADO-TORRES, 2007).

4 > SARANGO, 2014 (comunicação oral). 5 > SARANGO, 2014 (comunicação oral). Infelizmente, por uma questão altamente colonizada, só é possível fazer referência a pensamentos escritos. As importantes noções que conhecemos através da vivência e da experiência, podem, no máximo ser mencionadas em uma nota de rodapé, ao invés de citadas. Agradeço aqui a Luis Fernando Sarango, pelas conversas francas. 
$6>$ Esta exterioridade relativa à modernidade é um fator determinante para a compreensão da situação latino-americana. Tal exterioridade gerou o conceito de Pensamento fronteiriço, muito bem abordado nas obras de MIGNOLO (2003) e CASTRO-GOMEZ; GROSFOGUEL (2007).

7> A abordagem deste texto e do Pensamento Decolonial como um todo, não pretendem fazer um Tribunal de Nuremberg da ciência ocidental, pelo contrário, valoriza muitas de suas contribuições, porém, não pode deixar de atacar pesadamente suas contradições. Este texto, por mais modesto que seja, também é fruto da academia, mas, principalmente, é fruto de paradigmas outros de conhecimento.

$8>$ "Nós homens das diversas Américas permanecemos tão incomunicáveis que nos conhecemos apenas por referência, contados pela Europa" (Tradução nossa)
Sendo assim, o fato da ciência ocidental, mais especificamente a universidade, determinar qual conhecimento é válido e qual é invalido, baseando-se meramente em uma perspectiva ocidentalizada, suscita problemas graves para a interpretação da realidade de geografias que estão em exterioridade relativa à modernidade. ${ }^{6}$

\section{Estrutura Arbóreo e os Cânones das Disciplinas}

Já vimos que aqueles que estão em exterioridade relativa à modernidade, los de abajo, não produzem um conhecimento "equivalente" ao ocidental, devido à "pertinência" de alguns conhecimentos e a impertinência de outros. Como foi dito, a academia ocupa o cargo de validadora e de produtora de conhecimentos pertinentes. ${ }^{7}$ Sem negar as grandes contribuições que vem sendo desenvolvidas pelo meio acadêmico, pretendo apontar os pontos cegos das ciências sociais ocidentais dentro de sua grande instituição: a universidade, especialmente no que se refere à estrutura das disciplinas.

As estruturas das disciplinas científicas nas universidades ainda operam na mesma forma pela qual se consolidaram no século XIX. Isto é, rigidamente separadas umas das outras, comprometidas com a objetividade e a neutralidade. Não quero desconsiderar as inúmeras alternativas que vem sendo pautadas para permear esta continuidade, a ideia de transdisciplinaridade e de interdisciplinaridade vem sendo propostas com bastante vigor e consistência. Porém, ainda existem desajustes na estrutura de nossas velhas disciplinas.

Por reflexos do que se denomina Colonialidade do Saber, nossas disciplinas configuram-se sob o que Santiago Castro-Gómez denomina Estrutura Arbórea. Tal estrutura define "troncos" muito rígidos, encarregados de hierarquizar e de estabelecer fronteiras entre os saberes (CASTRO-GÓMEZ 2007, p. 81). Outro ponto constitutivo desta estrutura é o que Castro-Gomez denomina Cânones das Disciplinas, exemplo: Marx, Durkein e Weber são os pais da Sociologia; os "gregos" os pais da Filosofia; Newton, pai da Física. Isto é uma forma de fixar os conteúdos em torno deste tronco/eixo (CASTRO-GÓMEZ, 2007, p. 83-84). Além disso, elabora uma genealogia absolutamente intra-europeia destas disciplinas.

Ao perceber que a estrutura mais sólida e definida das disciplinas modernas é composta por autores exclusivamente intra-europeus, recordo-me de um apontamento feito por Jorge Luis Borges, ainda na década de 1930 (!): “[...] Los hombres de las diversas Américas permanecemos tan incomunicados que apenas nos conocemos por referencia, contados por Europa" (BORGES, 2012, p. 55)

"Nos conhecemos por referência, contados pela Europa"(!), frase tão violenta e tão precoce, da década de 1930 (!!), que desconcerta. É claro que não podemos negar a grande produção que vem sendo feita sobre a História e as Ciências Sociais em nuestra América, porém, a reflexão sobre o que é a História e as Ciências Sociais, enquanto representações, continua sendo feita a partir da Europa. O maior exemplo de que, em grande parte, abdicamos destas reflexões, é que a obra mais citada para apresentar a inequidade entre representações ocidentais e realidades "periféricas” é o Orientalismo, de Edward Said. A obra de Said é excelente, não há dúvida, porém, o problema consiste em que Said refere-se a questões especificas do Oriente; a América, todavia, não é abordada por ele. Considero que o peso de Said e dos autores pós-coloniais sob as Ciências Sociais Latino-americanas é de raízes eurocêntricas, já que, se busca no Oriente próximo e na Índia, soluções para as Ciências Sociais Latino-americanas. Por isso lembro que: a cultura "Oriental” foi digna de certo respeito por parte do ocidente, ao passo que as culturas americana e africanas, não o foram. Será que não estaríamos fazendo algo parecido? 
Novamente, insisto que interpretar problemas da nossa realidade, através de teorias forjadas por outros locus de enunciação, proporciona a resolução de nossos problemas apenas de maneira parcial ou distorcida. Sobre essa questão do locus, muitos podem se perguntar, se temos algo a ver com um grupo Q'echua, ou, se um grupo Aymara tem algo a ver com um grupo Guarany. É evidente que suas realidades são totalmente distintas, porém, o que nos aproxima, é a condição de Colonialidade ontológica (Colonialidade do ser), isto é, a internalização de algumas categorias de dominação epistêmica. Os estudos pós-coloniais partem da ideia de que o "dano" gerado pelo colonialismo se dá mais na esfera político-econômica do que epistêmico-política.

\section{História: a grande marcha da humanidade}

Pois bem, "nos conhecemos por referência", os saberes não ocidentais são sempre vistos com "desconfiança" e taxados como "conhecimento inválido". Por conta disso, ainda somos "contados pela Europa".

Sendo assim, somos representados através de narrativas universais pela História. Tais narrativas são fruto da hegemonia global da Europa, consolidada a partir do século XVIII. A partir de dois conceitos: Universalidade e Progresso, toda a história da humanidade foi distorcida e formatada como se fosse uma linha de tempo inquebrável. Walter Benjamin (2012, p. 246) diria que a história da humanidade se transformou em uma marcha e o destino final desta marcha - rumo ao progresso - era a vanguarda do mundo: a Europa Moderna.

O grande problema de ver a História como uma linha unidirecional e progressiva, é que, situando a Europa como a ponta desta "marcha", todas as outras formas de existência, para além das ocidentais, são situadas atrás da modernidade. É isso que Johannes Fabian (1983) denominou de negação da contemporaneidade no tempo, esta é a ideia que gera a noção de avançado/primitivo.

Como vanguarda da História, a modernidade europeia seria a forma de existência mais avançada e, paradoxalmente, a mais normal de todas as formas de existência (QUIJANO, 2005, p. 117). Citando o já referido trabalho de Quijano (2000), neste caso, a História foi utilizada para naturalizar, ao invés de atribuir historicidade a determinados fatos.

\section{Considerações finais}

Já vimos que as explicações historicistas contribuem mais para cristalizar processos históricos do que para lhes conferir historicidade. Por conta disso, é necessário que a disciplina de histórica atual venha a desnaturalizar e (res)significar a nossa sociedade. A História é uma importante ferramenta para deslocar o estudante para a alteridade, seja no tempo ou no espaço. Espero não dar a entender que deposito só na história esta responsabilidade, já que, essa deveria ser uma incumbência do sistema educacional como um todo, porém, mais especificamente, das ciências humanas.

Pois bem, no que diz respeito à Escola moderna, nascida para homogeneizar a população de um determinado território, atribuindo ao território nacional uma única territorialidade, é indispensável que se faça atuante uma perspectiva intercultural de educação. Não quero atribuir nenhuma conotação "mágica” à educação intercultural, porém, acredito no seu potencial para gerar estranhamento ao estudante, deslocando-o da "naturalidade do cotidiano". 
Primeiramente, gostaria de ter o cuidado de fazer uma crítica ao que é o multiculturalismo, de acordo com diversos autores, trata-se de uma apropriação comercial das culturas, vinculada à globalização no qual se consome a cultura ao invés de conhecer ou vivenciá-la. Para romper com as visões quiméricas, exóticas ou consumistas do que é o outro, é preciso não colocar estranheza onde não existe. Por isso, aprecio os trabalhos que visam a interculturalidade como uma maneira de se compreender e, de certa forma, vivenciar estes outros paradigmas.

Atribuo à questão da vivência um peso importante para formulação de uma educação intercultural, já que a vivência, isto é, o corpo, é atuante e fundamental para a formação intelectual, ao contrário da perspectiva ocidental, na qual o conhecimento se transmite exclusivamente pela alma - na ideia cristã ocidental - ou pela razão - na ideia cartesiana moderna (QUIJANO, 2005, p. 117-118). Deste modo, a vivência, permite ao estudante, participar de maneira mais integral da experiência intercultural. Por isso, é importante que a escola seja um local de trânsito e de diálogo entre várias culturas, em que os estudantes convivam com outros paradigmas de existência.

Por meio desta perspectiva, espero que a vivência proporcione ao estudante o estranhamento, isto é, a imersão em um espaço em que não se conhece bem as dinâmicas e a simbologia, permitindo-o conhecer outra ideia de território e de territorialidade, deslocando-o, enfim, para a alteridade.

Acredito que esta alternativa, que propõe o diálogo intercultural, proporciona um olhar não vitimador para as culturas e epistemologias não ocidentais. Já passamos do tempo em que a escola e os territórios deveriam ser homogêneos. Para citar os zapatistas, precisamos de "um mundo onde caibam muitos mundos"9.

\section{Referências $^{10}$}

BENJAMIN, Walter. Sobre o conceito de história. In: Obras Escolhidas: magia e técnica, arte e política. Ensaios sobre literatura e história da cultura. São Paulo: Brasiliense, 2012. v.1.

BORGES, Jorge Luis. Discución. Buenos Aires: Debolsillo, 2012.

CASTRO-GÓMEZ, Santiago. Decolonizar la universidad: la hybris del punto cero y el diálogo de saberes. In: CASTRO-GOMEZ, Santiago; GROSFOGUEL, Ramón (Org.). El giro decolonial: reflexiones para una diversidad epistémica más allá del capitalismo global. Bogotá: Iesco-PensarSiglo del Hombre Editores, 2007. p. 79-91.

CASTRO-GOMEZ, Santiago; GROSFOGUEL, Ramón (Org.). El giro decolonial: Reflexiones para una diversidad epistémica más allá del capitalismo global. Bogotá: Iesco-Pensar-Siglo del Hombre Editores, 2007.

FABIAN, Johannes. Time and the Other. New York: Columbia University Press, 1983.

GALEANO, Eduardo. O livro dos abraços. 9. ed. Porto Alegre: L\&PM, 2002.

MARCOS, Subcomandante Insurgente. Nem o centro nem a periferia: sobre cores, calendários e geografias. Porto Alegre: Deriva, 2008.

MALDONADO-TORRES, Nelson. Sobre la colonialidad del ser: contribuciones al desarrollo de un concepto. In: CASTRO-GOMEZ, Santiago; GROSFOGUEL, Ramón (Org.). El giro decolonial: Reflexiones para una diversidad epistémica más allá del capitalismo global. Bogotá: Iesco-PensarSiglo del Hombre Editores, 2007. p. 127-167.

$10>$ Transmito um grande saludo a todos integrantes do Grupo de Estudos Elisée Reclus, agradecendo por todas as experiências que proporcionaram o aprendizado do Pensamento Decolonial. E à Júlia S. Colla pela grande ajuda com a revisão.

MIGNOLO, Walter. Historias locales-diseños globales: colonialidad, conocimientos subalternos y pensamiento fronterizo. Madrid: Akal, 2003.

QUIJANO, Aníbal. Que tal raza!. In: ALAI: América Latina en movimeinto. 2000. Disponível em: $<$ http://alainet.org/active/929>. Acesso em: 17 maio 2015. 
QUIJANO, Aníbal. Colonialidade do Poder, Eurocentrismo e América Latina. In: Colonialidade do Saber: eurocentrismo e ciências sociais, Perspectivas latino-americanas. Buenos Aires: CLACSO, 2005. (Colección Sur Sur).

SARANGO, Luis Fernando. Cultura, latinoamericanidade e pensamento descolonial. Porto Alegre: UFRGS, 2014. (Comunicação oral).

WALSH, Catherine. ¿Son posibles unas ciencias sociales/culturales otras?: reflexiones en torno a las epistemologías decoloniales. Nómadas, n. 26, p. 102-113, 2007. Disponível em: $<$ http://www.redalyc.org/articulo.oa?id=105115241011>. Acesso em: 16 abr. 2015. 
